\title{
FINANCIAL VULNERABILITIES FOR SMALL ENTERPRISES IN KERALA
}

\author{
Adithi Pradeep ${ }^{1,}$ Dayana Das ${ }^{2}$ \\ ${ }^{1}$ Department of Commerce and Management, Amrita School of Arts and Sciences, Amrita Vishwa Vidyapeetham, \\ Amritapuri, India \\ ${ }^{2}$ Department of Commerce and Management, Amrita School of Arts and Sciences, Amrita Vishwa Vidpyapeetham, \\ Amritapuri, India
}

\begin{abstract}
The small and medium-sized enterprises sector is an important segment of the Indian economy. Results of Third All India SSI unit censuses show a declining growth trend at the All India level and a growing trend in the Kerala sector. With the exception of the Fourth Census, employment growth in the Kerala SME sector has shown an increasing trend. Growth in the SSI Sector can do a lot to solve Kerala's acute unemployment problem. Sickness among the Kerala SME units is a major problem.
\end{abstract}

Keywords: All India Census of Small Scale Industries, kerala, MSMEs, Growth Rate, Sickness.

Article Received: 10 August2020,Revised:25October2020,Accepted: 18 November 2020

\section{INTRODUCTION}

With the beginning of the globalization cycle, the Indian Small and Medium Enterprises (SMEs) are lingering behind the adversary firms. The opponent firms start from the neighbouring nations regarding send out seriousness. The primary explanation credited behind this is absence of utilization of refreshed innovation and other prominent reasons. Henceforth, this calls for critical activity. A customary fare situated industry confronting intense rivalry from the other engineered items created by its adversaries. The fare esteem has not seen an immense increment, which is clear from the fare pattern from the most recent 5 years. Innovation can upgrade seriousness. Some hypothetical bits of knowledge on innovation and fare intensity, and innovation move channels have been expounded. Conversation and assessment Absence of fitting innovation will decrease the capability of SMEs, bring down the interest for the items changing to unrivalled quality from opponents and lower the net revenue. There should be a solid spotlight on executing the new age innovation, through better mindfulness, embracing of best works on, creating indigenous innovation just as mechanical cooperation with worldwide accomplices. The Government of India has been dispatching a few SME plans identified with innovation every occasionally. Notwithstanding, more

should be finished. More endeavours as higher interest in innovative innovation and innovative work, higher use of advanced and innovation empowered stage, move of innovation, greater interest in HR, improved admittance to fund, decreased infrastructural holes, and lesser severe business guidelines can help in improving the intensity of the SMEs.

\section{OBJECTIVES OF THE STUDY}

- To contemplate and analyse MSME function in India

- To contemplate issues and difficulties looked by SME's in India

- To Construct a reasonable model connecting issues and difficulties

- To examine the idea, nature, and function of business and idea of SMEs in India.

- To analyse the financial exhibition like speculation, wellsprings of borrowings, credit strategy, productivity, share in fare and so forth of Small Enterprises. 
- To Study the impact of difficulties on these Enterprises

\section{BACKGROUND}

The previous decade noticed a snappy globalization of financial movement and this globalization measure has expanded the criticalness of cross-fringe collaboration regarding advancement. The advancement movement is being done as far as acquiring contributions for development (thoughts, account, abilities, innovations) from abroad and in exploit its yields (items and administrations, licenses, licenses, and so on) in abroad business sectors.

An aggregate number of firms, nations and other monetary entertainers are participating in the present global economy. Globalization is ending up being an aid in a more effective portion of assets across nations, remembering increment for profitability, effectiveness, normal salaries, compensation, more noteworthy rivalry, lower costs, expanded item assortment and quality. Globalization is giving associations a prevalent serious position and bringing down the working expenses. In conclusion, globalization has prompted enhancement of assets, formation of new venture openings by opening up extra business sectors, and getting to new crude materials and assets. Against this background, the Brazil, Russia, India, China, South Africa (BRICS) nations have become critical parts on the planet market. About the Indian Economy, the Indian SMEs frantically need to enter the worldwide market and set up a critical situation for their items.

\section{Background of Indian SMEs}

The Indian SME are perceived as a significant supporter in the monetary development. It is supposed to be the foundation of the Indian economy. It has given versatility to avoid worldwide monetary stuns and difficulties. Almost, 20\% of the Indian SME are based out in the provincial zones of India and keeps on giving business occasions to almost $40 \%$ of the India's workforce. As indicated by Reserve Bank of India (2019), in the year 2017-18, the SME area involved in excess of 52 million undertakings utilizing in excess of 130 million people. The SMEs make in excess of 9000 items. This includes a wide reach from the customary items to complex items (as far as innovative things).
The Report of the Working Group on Small and Medium Enterprises (SMEs) development for twelfth long term Plan (2012-17), discloses that the area represents $45 \%$ of the assembling yield and $40 \%$ of the all-out fares of the nation. Further, the Ministry of SME's (2017) features that the smes represented $30.74 \%$ of GDP in the year 2014-15. Current monetary gauge or review deciphers that with the Indian Economy developing at a normal of 7\% per annum; it is probably going to turn into a $\$ 5$ trillion economy continuously 2025 . Henceforth, the advancement of the SME area is gets fundamental as is viewed as the foundation of India.

In any case, in hate high development rate and great possibilities, the Indian SMEs have been dependent upon specific imperatives. The most prominent hindrances are absence of ideal credit, Procurement of crude materials at serious cost, deficient framework offices including power, water, and street, and absence of talented labour for assembling, administrations, promoting, and so on the main requirements looked till date are innovative backwardness. The Indian SMEs need state-of-the-art data and are frequently uninformed about the most recent advancements present in the worldwide market. Occasionally they need administrative abilities, enterprising information and innovation escalated training to run an able

This kind of issue typically wins in the country-based territories. It is said that the Information Communication and Technology (ICT) can assume a greater part for SMEs as they face stiffer rivalry from their opponent neighboring nations (China, Indonesia, Philippines and Thailand). Subsequently, the need of great importance is up-gradation of innovation.

For Indian SMEs to get serious, it needs to embrace the best worldwide rehearses and continually redesign its innovation. It is regularly discovered that the principle challenge for some, SMEs is to develop right abilities and the board rehearses for building up and incorporating information made by outer accomplices with in-house practices and advancement measures (OECD 2013).

\section{Rationale for technology up-gradation}

1) The SMEs occupied with non-industrial nations regularly produce customary things (substandard quality) went with low profitability. They chiefly 
oblige the little neighbourhood markets. Thus, a quickened specialized change inside a limited capacity to focus of time making the SMEs hard to build up an upper hand in the worldwide market.

2) International innovation markets are blemished, and finding the correct innovation in the correct way is a significant awkward undertaking. Likewise dominating of another innovation includes gaining new abilities, materials and strategies, which can dubious and an expensive cycle. Receiving and developing innovation are basic to the accomplishment of SMEs during the time-spent internationalization. SMEs should be utilize the most recent advancements to create effective and great creation, and contend in the worldwide market. The new ideas, for example, cloud computing, which empower agreeable sharing of assets, will assist more modest firms, with utilizing on the cutting edge innovations. Such courses of action let loose basic assets of SMEs, and lead to even more zeroing in on the centre exercises.

3) Lack of access and interest in innovation obstructs the capacity of SMEs to contend in worldwide business sectors. Innovation is a critical differentiator for the SME area to remain all around the world serious. With the progressing worldwide pattern, Indian SMEs has their own arrangement of difficulties identified with innovation selection and size of activities.

The other convincing explanations for selection of new/trend setting innovation are prerequisite to cling to administrative standards identified with (i) gushing release standards (ii) product quality confirmations (homegrown/sends out) and so forth might be a pre-imperative for SMEs to keep providing to worldwide business sectors with exacting administrative guidelines, strategy uphold and various plans executed by Government bodies in helping innovation up-gradation, need for up-gradation of innovation and withdrawal of upkeep uphold for existing innovation may constrain SMEs to receive new innovation, and finally, absence of accessibility of essential degree of abilities among the workforce in any event, for typical positions a conspicuous explanation for SMEs for quick innovation reception.
Nevertheless, SMEs may neglect to take the total favorable circumstances of globalization assuming a few extra boundaries exist, for example, absence of computerized admittance, lacking assets or information to enhance the item quality, failure to bring down the fare costs, higher unit cost of creation, educational bottlenecks, lacking methodology for displaying and promoting.

Globalization ordinarily brings about free development of merchandise and ventures over the fringes. High levy dividers (for example Import duty, shares or willful fare restrictions) forced by the bringing in countries, may forestall the SMEs to contend in the worldwide market. Once more, there might be circumstances where SMEs creating material merchandise face an extreme rivalry with their adversaries delivering manufactured items. The opponent may catch a higher piece of the pie with the utilization of more significant level of innovation and gifted labour. The Indian SME may neglect to contend in such circumstances.

\section{LITERATURE REVIEW}

Numerous studies have discussed the role of SMEs in a competitive market.

Mukherjee (2001) who presented an outline of the role of SMEs, challenges posed by the several global forces, changes in the policy environment of SMEs, selected World Trade Organization (WTO) agreements in the context of SMEs, possibilities of legitimate cover of protection under WTO rules and policy recommendations restrictions affecting SMEs are access to credit, technology and red-tapism and concluded that the key matters should be removed to make the SMEs perform better. The choices available to SMEs are associated with the quality of institutions, markets and organizations and it is the productivity and efficiency of the institutions, markets and establishments that boost or dampen SMEs to take their signs for learning novel ways of doing business, compare their own competitive features with their rivals, including launch of new innovations into their business plans. (OECD 2004:9). Globalization brings risks and hence SMEs are unlikely to survive in their current form. They need to improve their standards and quality, cost competitiveness and other management practices (Hwang 2007). Asian Development Bank (2009) highlighted a few constraints such as limited access to finance, scarce medium and long-term finance, restricted connectivity to markets, insufficient physical infrastructure, 
underprivileged women entrepreneurs, and absence of credit rating information system for SME borrowers in context of SMEs. However, Harvie (2010) emphasizes that SMEs need to improve their international competitiveness, particularly in terms of Research \& Development, improved quality control, and skills. He also argues that governments should promote the development of local parts and supplier industries. This is likely to be an effective strategy to expand the domestic content of Multinational Company operating in a country. The development of networks of domestic suppliers, along with access to and availability of finance, together with increased linkages between SMEs and large firms, are critical. Dalberg (2011) stated that SMEs has provided over $60-70 \%$ of total employment, $55 \%$ of GDP in the Organization for Economic Cooperation and Development (OECD) economies. Das and Joseph (2013) discussed that India is a home to a number of natural industrial clusters mainly dominated by SMEs and subcontracting has been promoted through a number of measures such as learning, innovation and competitive building systems. However, the real outcome is yet to come. Lastly, Mesut Savrul (2014) examined the fact that the size of the SMEs has put them in a disadvantageous position. However, for Small and Micro Enterprises (SMEs) to compete in global platform, e-commerce can help them to overcome the several obstacles and barriers that limit or prevent them from getting into e-commerce. It is up to the SMEs to implement competitive business operational practices and strategies.

\section{THEORETICAL INSIGHTS: HOW TECHNOLOGY CAN BOOST SMES?}

Innovation is progressively observed as business empowering influence and is a fundamental device for acquiring measure efficiencies and more significant level of normalization. With the goal for SMEs to build up an upper hand to wander into the worldwide market and work there, the Indian SME needs to set up them in the homegrown market. There should be a solid spotlight on executing the new age innovation, creating (indigenous innovation) just as mechanical cooperation with worldwide accomplices to assume a critical job. The Technology assumes an essential part for SMEs to assist them with confronting the solid rivalry from huge endeavors and imports. A solid innovation empowered area makes everything fair largely among SMEs and their set up partners universally.

Businesses are getting increasingly lithe and innovations, for example, online media versatility, examination and distributed computing are meeting up to release the incredible worth and opportunity. This union is likewise called Social Media, Mobility, Analytics (SMAC) and Cloud Computing and will arise as a key business empowering influence throughout the following not many years. In this unique circumstance, the Indian SMEs are slowly embracing the SMAC (higher among the metropolitan undertakings). The other driving elements, which will help the SMEs in setting up themselves in the worldwide markets are SMEs government uphold, use of outside administrations, adequate admittance to back and utilization of human aptitudes and assets.

The Indian SMEs entering the global market need to acquire a particular cost known as sunk expenses. Aside from this, they likewise need to know the taste and inclination of the shoppers requesting their item in the global market. SMEs creating an unacceptable result of second-rate quality utilizing outdated innovation will not have the option to contend in the worldwide market. Clients are ordinarily very much aware of the items accessible on the lookout. The interest for the item will be insignificant if there is lesser measure of displaying, promoting and mindfulness. With the assistance of predominant innovation, huge measure of selling and promoting use, and displaying, the Indian SME can offer an unrivalled nature of item and support itself in the serious worldwide market.

\section{CHANNELS OF TECHNOLOGY TRANSFER}

The prompt answer for innovative headway might be accomplished through innovation move, through one or the other level or vertical exchange. Notwithstanding, given the idea of size of activity of Indian SMEs, it is hard to cause a higher use on R\&D exercises. It is likewise hard to get a development level of assembling innovation because of their significant expenses (Government of India 2010).

There are various channels for innovation to be moved both universally and locally. The primary global innovation move channels are through Foreign Direct 
Investment (FDI) done through consolidations and acquisitions, specialized authorizing contracts among abroad and local firms, imports of moderate and capital products, venture contracts, specialized consultancies by abroad organizations and consultancy firms. All these innovation move components will in general effect just the metropolitan based and greater to medium measured ventures.

The fundamental exchange innovation components incorporate:

(i) Technology Licensing through which the gatherings that give and take the execution and use rights go into a permitting contract, and on the reason of the predetermined conditions including instalment of specialized expenses for a predefined period and so forth the consent for the execution and use rights is given.

(ii) Technology deal: By innovation deal unlimited oversight and organization is given over to the purchaser who addresses the cost (deals value).

(iii) Technology Transfer with capital administration.

(iv) Technology Transfer utilizing specialized individual as the medium incorporates greeting and arrangement of specialized faculty, goal of innovative issues through the work of specialized faculty etc.

(v) Technology Transfer including offer of innovation information, for example, plans, drawings and so on which is ordinarily more important for little scope ventures used to rearrange mechanical arrangements.

\section{DISCUSSION}

Nonattendance of suitable innovation will diminish the capability of SMEs and they will fall behind different opponents in the worldwide market. Different impediments will be lower interest for the item, replacement to other unrivalled quality items delivered by rival firms and lower net revenue (at times misfortunes prompting closure).

Innovation is progressively observed as business empowering influence and is an essential apparatus for getting measure efficiencies and more serious level of normalization. With the end goal for SMEs to build up an upper hand to wander into the global market and work there, the Indian SME needs to set up them in the homegrown market. There should be a solid spotlight on actualizing the new age innovation, creating (indigenous innovation) just as mechanical cooperation with worldwide accomplices to assume an essential job. Innovation is a vital differentiator for the SME area to remain universally serious.

The Government of India (GOI), and other SME pioneers have perceived the issues related with innovation and other related difficulties (absence of foundation, HR and admittance to capital, and so forth) these provokes should be dispensed with to support a sound development of Indian SMEs and further improve their commitment in the worldwide market. With the GOI dispatching a few SME schemes, little ventures in the rustic territories are yet to exploit the accepted procedures accessible at the mechanical front. Innovation as a distinct advantage and better help with doing facilitate business is yet to be figured it out. With the expansion of innovation related plans, there has been an ascent in innovation selection.

\section{OTHER CHALLENGES FACED BY THE SMES}

With dexterity and dynamism, the Indian SME area has indicated praiseworthy development and versatility to the ongoing monetary slump and downturn. For instance, the GOI, have as of late embraced the grouping and systems administration way to deal with assistance these SMEs to improve their intensity in the hardest occasions. Indian SMEs are likewise actualizing new and creative data and correspondence innovations for a huge scope like Software as a Service, and Infrastructure as a Service to adapt up to troublesome circumstances. Notwithstanding these measures, the Indian SMEs are confronting incredible difficulties in the time of globalization and advancement. A portion of the striking difficulties is recorded underneath:

1) High expense of credit: Access to satisfactory and convenient credit at a sensible expense is the most basic issue looked by this area. Late examinations on this zone by analysts (Levy 1993, Basu 2004, Seshasayee 2006, Das 2008 and Nagpal et al.2009) demonstrate the Indian SMEs are prevented by imperative of helpless credit accessibility. The significant purpose behind this has been the high 
danger observation among the banks about this area and the high exchange costs for advance examination. Further, major parts in SME area are not in a situation to give insurance to benefit advances from banks and thus denied admittance to credit.

2) Procurement of crude materials at a serious cost: The accessibility of fitting financial assets is significant for business improvement (Tustin 2003: 126, Goodall 2000a: 15, Czinkota and Ronkainen 2003:49). The fundamental mastery and crude materials to try enterprising thoughts, to be serious, make due during horrible conditions and to develop (Robertson et al. 2003:313; Wickham 2001: 71). This is a developing test looked by this area as obtainment for crude materials is completed inside neighbourhood domain because of their monetary imperatives and acquisitions are a lot more modest in scale when contrasted with industry on the loose.

3) Inadequate framework offices, including power, water, streets, and so on Absence of intensity/power foundations adversely influence the efficiency and benefit of assembling SMEs (Adelekan 2005; Akinwale 2010; Doe and Asamoah 2014). To guarantee seriousness of the SMEs, it is basic that the accessibility of framework, innovation and talented labour are in line with the worldwide patterns. SMEs are either situated in modern bequests set up m any many years back or are working inside metropolitan regions or have come up in a disorderly way in country regions. The condition of foundation, including power, water, streets, and so forth in such regions is poor and temperamental.

4) Lack of gifted labour for assembling, administrations, promoting, and so on insufficiencies in the inward market climate are the fundamental driver of SME disappointments and rotate around administrative aptitudes, information on money, and negligible skill in showcasing and HR (Ligthelm and Cant 2002). In spite of the fact that India has the advantage of a major pool of HR, the business steadily faces shortfall in labour with abilities set needed for assembling, promoting, adjusting, and so forth.

IX. MEASURES TAKEN TO PROMOTE THE INDIAN SME IN THE GLOBAL MARKET
The techniques taken to improve the assembling capacity of the SME area is relied upon to improve the intensity of their items and upgrade the fares. Measures, for example, higher worth expansion, bunch advancement, ability improvement and preparing, push on normalization and quality, admittance to moderate credit, impulse for development would be fundamental measures to advance the intensity of the Indian SMEs.

\section{Cluster development}

The Ministry of SME has received the group development6 approach as a vital system for improving the profitability and intensity just as limit working of SMEs and their aggregation in the nation. The goal is to get to the most recent devices, innovation, plan, and testing offices for such ventures, update infrastructural offices. The advancement of groups has become a mainstream method for advancing seriousness in SMEs and this has been energized through existing or possible agglomerations by arrangement of appropriate foundation, advancement of linkages among SMEs and with huge firms, consolation of nearby help organizations.

\section{Access to credit}

As far as convenient admittance to satisfactory credit has been agreed a high need for the SMEs. To address this issue, more inclusion have been made under Credit Guarantee Fund Scheme. The units under the classification of Micro and Small Enterprises would now be able to profit guarantee let loose credits to Rs. 2.00 crore through select monetary establishments. Various new businesses in the working capital space are likewise attempting to make it helpful for SMEs to get to credit absent a lot of trouble. As of late, the presentation of MUDRA as a particular window with the point of focusing on the miniature ventures is a significant mediation made for expansive basing account. The MUDRA credits are considered as a huge expansive bases monetary structure.

Technological development 
The Prime clergyman's team on SMEs, set up under the chairmanship of the key secretary T.K.A Nair has proposed measures which incorporate the need to refine the current FDI strategy to build limit, capacity and innovation advancement. The gathering likewise concurred that there is a need to build up a harmonious connection between the SME bunches and specialized organizations. In addition, to address advanced difficulties what's more, to embrace innovation up-gradation, obtaining, transformation and advancement, an innovation improvement asset of Rs. 1000 crore, has additionally been proposed. The Ministry is likewise zeroing in on very good quality skilling and innovative help through 18 Tool Rooms and Technology Development Centre the nation over. The Ministry of SMEs has distributed a measure of Rs. 2200 crore with the help of the World Bank. This will empower it to build up 15 New Technology Centers (TCs) under Technology Centre Systems Project to improve the general profitability of the SMEs. Moreover, there is likewise a Credit Linked Capital Subsidy conspire

\section{Government schemes}

A large group of different activities, for example, MakeIn-India, Digital India, Start-Up India and Skill India for the comprehensive development of the Indian SME area have been taken by the Government of India (GOI). The Make-In India was dispatched in September 2014 and is a more extensive arrangement of country building activity. The fundamental target was to change India into a worldwide plan and assembling center. The Make in India is an alternate sort of crusade. It gives structure to a huge measure of specialized data on 25 industry areas and contact a huge neighborhood and worldwide crowd by means of web-based media and continually keep them refreshed about circumstances, changes and so on The Digital India transformation gives a plentiful occasion to advancement of SME and furthermore more noteworthy cooperation of SME in the Information, Communication and Telecommunication (ICT) area. Computerized empowered innovations can additionally permit SMEs to build up their own market insight, spread scale without mass and access worldwide business sectors and information networks at generally ease. The computerized progress encourages the rise of "brought into the world worldwide" private ventures and gives new occasions to SMEs to expand their intensity in nearby and worldwide business sectors, through one or the other item or administration advancement. The utilization of advanced innovations can likewise facilitate SME's admittance to abilities and ability, through better occupation enrolment locales, redistributing and online assignment recruiting, just as association with information accomplices (OECD 2017f). Aptitude India crusade was dispatched by Prime Minister on 15 July 2015 to prepare more than 40 crore individuals in India in various abilities by 2022 . There are a few activities under this mission, for example, National Skill Development Mission, National Policy for Skill Development and Entrepreneurship, 2015, Pradhan Mantri Kaushal Vikas Yojana, Skill Loan Scheme, and Rural India Skill. UK has gone into a joint effort with India under the ability India program.

\section{Adopting corporate governance practices}

Powerless corporate administration of little firms, troubled further with helpless accessibility of critical information sources, has made these organizations incredibly powerless. Great administration rehearses in SMEs will assist them with developing or pull in extra financial specialists. Raising capital has, for a long time, been viewed as the significant test confronting SMEs. The nonappearance of good corporate administration rehearses makes it hard for them to get to fund from banks or speculators. Selection of corporate administration system by SMEs in India is basic for taking this area to a high development direction.

\section{Development of human and natural resources}

Human asset advancement issues are major to improving SME intensity. Observational investigations show that human resources is a critical determinant of development. The capacity of SMEs to acclimate to the serious weights that accompany exchange advancement and globalization will rely upon the degree of aptitudes accessible locally. A significant worry in the Indian setting is the low profitability and administrative capacity of SMEs and the lower ability levels of the SME laborers. The human asset requirements have been influencing both the proficiency and profitability of Indian SME area.

\section{GOVERNMENT OF INDIA MEASURES}

The GOI had taken a few activities in the field of Intellectual Property Rights (IPR), remembering alterations for patent laws and development of the 
IPR/Patent Offices, as a vital reaction to the globalization of the economy. In an item patent system, Indian firms should relook for more up to date wellsprings of development. Improving mindfulness on IPR among organizations, especially SMEs, implies that they will have the option to settle on educated choices for ensuring their thoughts and business techniques. The Ministry of Miniature, Small and Medium Enterprises (SME) in India is leading workshops on different parts of WTO, Antiunloading classes, IPR, and so forth to sharpen the Medium and Small Enterprise (MSEs) business visionaries and different partners about the presumable effect of advancement and globalization.

The Finance Minister of India in the impending financial plan proposed to decrease the expense pace of SMEs announcing turnover of not as much as Rs. 50 crore to $25 \%$ from the current $30 \%$. She proclaimed that this advantage would cover $96 \%$ of Indian organizations documenting annual government forms in India. Additionally, in a drive to advance computerized method of working together, a lower charge pace of $6 \%$ has been proposed to little Indian organizations having turnover of not as much as Rs. 2 Crore. To extend the current market size of SME, it was recommended that the Ministries and Departments of Central Government will get $20 \%$ of products and ventures from Micro and Small Scale Enterprises as a piece of Public Procurement Policy, MSE request 2012. The Government of India is further firming up its current strategies through different new declarations and activities. For instance, a piece of the Ease of Doing Business and to formalize the SME area, Udyog Aadhar Memorandum (UAM) was advised in September 2015. The framework offered page single guide enlistment toward evade delays and is viewed as one of the way breaking activity.

With the declaration of the 'One Nation One Tax' approach under Goods and Service Tax, Indian SME can release their genuine potential. For improving the seriousness of the Indian SMEs, National Manufacturing Competiveness Program has been dispatched. The goal of the plan is to improve the worth chain of the SME area and make it more proficient and serious in the worldwide market. In conclusion, the GOI have dispatched plans/programs for innovation up-gradation, advancement of bunches of such ventures, making guarantee free bank credit accessible up to US\$ 1, 25,000, making mindfulness among these businesses with respect to send out related issues, and so forth.

\section{CONCLUSION AND FUTURE MEASURES}

The point of this examination was to make a top to bottom investigation of how Indian SMEs can withstand itself in the worldwide market in spite of the various difficulties in the different structures. It was discovered that there are various difficulties pervasive in the Indian Economy, for example, significant expense of credit, trouble of obtainment of crude materials at a serious cost, insufficient infrastructural offices, and absence of talented labor. It uncovered that in spite of the fact that fares have expanded in the worldwide market, the fare profit have not expanded a lot throughout the most recent years. It is commonly observed, that innovative advancement assists with separating an item from its contenders/rivals item. The GOI has set aside a few measures from effort to time for innovative advancement of the Indian SMEs so it can improve its seriousness in the worldwide market. To counter different difficulties as well, new plans and projects, for example, Make-In India, Skill India and Digital India have been dispatched throughout the long term.

The discoveries show that despite centering in the advancement of innovation-based items the other significant difficulties additionally should be tended to all the while. Moves, for example, admittance to credit, advancement of sufficient framework (power, power), gracefully of crude materials and preparing of workers to be recruited by the SMEs likewise exist. Thus, every one of these difficulties are needed to be tended to all the while for the general achievement of Indian SMEs in the fare market. Ultimately, the investigation will direct the SMEs who are yet to enter the worldwide market with regards to what are the provisional difficulties, how they can be survived and by what method can the GOI help them in entering the worldwide market over the long haul.

To stay serious and increment the offer in the globalized world, the Indian SMEs need to reliably redesign their innovation in the ever-changing globalized world. The Indian SMEs may utilize outer specialists or resort to different measures consistently. Indian SMEs can likewise settle on innovation move such as vertical innovation transfer10 or even innovation move. The flat innovation move is the most widely recognized marvel among the SMEs since it can achieve various assignments through the

www.psychologyandeducation.net 
even innovation move. Subsequently, it is normal that through differentiated utilization of innovation separated from utilizing the other significant components of creation, the SMEs can upgrade their profitability, lessen their expenses, grow their size of creation, resort to new item improvement, increment their item deals and piece of the overall industry and most significant enter into the worldwide or global market.

In conclusion, if the Indian Economy is to continue a development pace of 8 to $10 \%$ in the coming decade, a solid and lively SME area is passionately required. Indian SMEs can possibly become worldwide endeavors. Consistent endeavors in different structures and dynamic GOI uphold/plans should help the Indian SMEs to become global parts in the coming decade. India ought to progressively grasp an organization of advancement and increment their association with other exploration establishments, colleges and different associations. The Indian SME area needs more data, direction and offices for ensuring their scholarly powers and show a positive methodology towards creation, insurance and the executives of IPR to contend in the worldwide market and experience a business development. This will additionally inspire and empower towards the starting of the IPR proposition in the Indian Economy.

The Indian expense framework has been reprimanded along a few lines as to be regarded unwanted for the business climate, number of installments required, and technique for recording installments and non-consistency across states related with tax collection (Ease of Doing Business Index, International Finance Corporation, World Bank 2014). The Simplicity of Doing Business has essentially improved from 131st situation among 190 nations to 130th situation in 2018. The improvement of the Ease of working together can be shown as a decent marker for the helpful execution of Indian SME. The Government of India is completely mindful of the difficulties of globalization and has taken suitable measures for setting up the SME to address the difficulties of advancement and globalization. All these consolidated future estimates will help the Indian SMEs get improved admittance in the worldwide business sectors.

The Limitation of this exploration lies in the way that there are information impediments. An essential review of some chose Indian SMEs might have helped us in the better comprehension of how really SMEs work in the worldwide climate. In future, an investigation can generally be led through an example study where some chose SMEs are covered. From now on, information about their age, skill, deals, import of crude materials, apparatuses, innovative work use, other assistance-based factors like (Information Technology experts, promoting and advertising consumption) can be gathered. In conclusion, an econometric exercise should be possible to inspect the reasonable effect of the factors on the intensity of the Indian SMEs. In future, a more experimental exercise with negligible information constraints could be a potential expansion of this investigation.

\section{REFERENCE}

\section{Articles from journals}

- Mukherjee1, Sonia. "Challenges to Indian Micro Small Scale and Medium Enterprises in the Era of Globalization | Journal of Global Entrepreneurship Research | Full Text." Journal of Global Entrepreneurship Research, 2AD, $\quad$ https://journaljger.springeropen.com/articles/10.1186/s4049 7-018-0115-5.

- Adelekan, IO., et al. "Challenges to Indian Micro Small Scale and Medium Enterprises in the Era of Globalization." Journal of Global Entrepreneurship Research, Springer, 1 Jan. 1970 , journaljger.springeropen.com/articles/10.1186/s4049 7-018-0115-5.

- Dayana Das, Dr. (2019). Innovations in pipeline " Consumer and entreprenur retrospectives on startups in kerala". Retrieved from

https://www.jardcs.org/abstract.php?id=1445 Indian Journal of public health research and development.

\section{Internet}

- 2021. [online] Available at: <https://www.researchgate.net/publication/3 28032529_Challenges_to_Indian_micro_sm all_scale_and_medium_enterprises_in_the_e 
ra_of_globalization> [Accessed 21 January 2021].

\section{Books}

- Neetu Bala., (2007),"Economic Reforms and Growth of Small Scale Industries", Deep and Deep Publications, New Delhi, Ch. 1, pp6. 